\title{
The Degree of Using Entrepreneurship Strategies in Higher Education Institutions in Israel from the Viewpoint of Their Employees
}

\author{
Prof. Linda fuad safoury
}

\begin{abstract}
This study aimed at identifying he degree of using entrepreneurship strategies in higher education institutions in Israel from the viewpoint of their employees, and to achieve the study objective; the researcher used a questionnaire consisted of (15) items divided into three fields, and it applied to a random sample consisted of (102) employees, during the first academic semester 2020/2021. The study findings showed that the reality of using the strategy of excellence in higher education institutions in Israel from the point of view of its employees came to a high degree, while the reality of using the risk strategy in higher education institutions in Israel from the point of view of its employees came to a medium degree, and the reality of using the innovation strategy in higher education institutions in Israel from the point of view of its employees came to a high degree.
\end{abstract}

Keywords: entrepreneurship strategies, higher education institutions, employees

DOI: $10.7176 / \mathrm{EJBM} / 13-3-10$

Publication date: January $31^{\text {st }} 2021$

\subsection{Introduction}

All higher education institutions aspiring to progress and prosperity seek to develop their educational systems and achieve a competitive advantage that contributes to improving the educational learning process outcomes. By providing all the human and material resources necessary to improve the product, improve the efficiency of operations, and in the midst of globalization and its multiple effects, the interest of universities has increased in applying entrepreneurship strategies, to control operations and improve outputs, this requires studying the reality of using entrepreneurship strategies in higher education institutions.

Today, the world is witnessing a scientific revolution and a vast civilized technological renaissance characterized by rapid progress and entrepreneurship, which includes the organization's development of programs and plans that help it to exploit opportunities that are characterized by uniqueness, and this is called external entrepreneurship, and entrepreneurship within the organization is represented by creating new business or strategic renewal in it, and this is what It is called internal entrepreneurship. Internal entrepreneurship has become a vital mean for existing organizations to continue to discover and exploit opportunities for the development of organization and individuals, and to achieve creativity, especially after the increased need for organizations to be more innovative in order to survive and accelerate growth in a highly competitive global environment. Organizations have tended to link entrepreneurship and strategy to achieve outstanding performance, improve performance and production, external alliances, organizational learning and resources, creativity, and leadership are achieved and developed in organizations that are seriously committed to generating innovations in a cumulative manner. The application of entrepreneurship strategies in organizations achieves a competitive advantage. Entrepreneurial organizations are able to systematically and continuously support innovations, and entrepreneurial behavior is needed by all organizations to keep pace with development in a highly competitive environment (Abdel Fattah, 2016).

Despite the interest of many theorists in the concept of strategy more than the concept of entrepreneurship, however, at the beginning of the third millennium, a great emphasis was placed on the concept of strategic entrepreneurship, which spread widely during that period and which was known under the name of integration between leadership and strategy (Katana and Agha, 2012). And the application of entrepreneurship strategies includes a set of entrepreneurship procedures such as (innovation, uniqueness, focusing on opportunities, the organization's interaction mainly with actions of a strategic nature, and creating a competitive advantage) (Hitt, 2007).

the researcher believes that attention must be paid to the application of entrepreneurial strategies in educational institutions due to technological progress and the emergence of globalization and privatization, which have a great impact on the internal and external strategic environment of these organizations.

Entrepreneurship strategies can be defined by the efforts made by the organization to achieve superior performance through the adoption of strategic activities that ensure the achievement of pre-defined goals (Ireland, 2003). Strategic entrepreneurship is the future vision related to the achievement of the organization's goals and adding real value to the achievements (Kuratko, 2014). The leadership strategies are based on identifying and investing opportunities, entrepreneurship challenges and treating them, and taking advantage of the internal and external environment of the organization in developing its business. And strategic entrepreneurship is the 
mechanism that identifies opportunities and exploits them, responds to environmental changes, creates and maintains a competitive advantage (Kavousy, 2010). Strategic leadership is united by a set of dimensions, the most important of which are: (creativity, uniqueness, innovation, and risk).

Organizations of all kinds, from small and medium-sized to large, including universities, seek to adopt strategic activities to achieve an entrepreneurship status in the society in which the organization work. And due to technological progress and development of the means of production, the tools of progress have become diverse and easier. Small organizations, as a result of technological development, can significantly improve their internal operations and may outperform large organizations, so the current attitudes of organizations are focused on creating value-added work to achieve entrepreneurship, with focus on the fact that achieving entrepreneurship requires managing human resources and capital, and managing programs and plans in a unique and creative way (Al Douri, 2014).

Entrepreneurship is based on a set of strategies, which can be presented according to (Kit, 2018), (Ali, 2017), and (Abdel Fattah, 2016) as follows:

The first strategy: a risk-bearing strategy, which means the management's ability to take risks in order to achieve performance within its primary activity in which it operates, and it seeks to achieve organizational goals, as the management must have some informational advantages in relation to the variables that arise from risks in order to achieve its objectives.

The second strategy: the strategy of seizing opportunities, which means the ability of the administration to distinguish and identify opportunities that meet its ambitions by owning the organizational models and depending on an insightful forward-looking vision and to capture opportunities that others may see as confused and hazy while seeing it as a promising opportunity, depending on its entrepreneurial capabilities.

The third strategy: the creativity strategy: the creativity strategy is based on investing the distinctive and creative ideas provided by the members of the organization, which can provide added value for services, and it means the ability to find new ideas and methods that contribute to enhancing the outputs.

Fourth Strategy: Innovation Strategy: It is an activity to innovate and develop a new product or new process.

Fifth Strategy: The Imitation Strategy: It is the process of adopting the creative processes that individuals use in their work.

The fifth strategy: the uniqueness strategy, and there are those who call this strategy the strategy of excellence and the concept of uniqueness for the organization comes through distinguishing it from other organizations through its ability to be the best choice for customers and workers. This uniqueness may be perceptible through branding, quality, organizational values and marketing experience.

Sixth strategy: proactive strategy is one of the most important characteristics of the entrepreneurial organization, which implies the desire of senior management for the organization to be the first to respond to the needs of customers and satisfy their needs and desires, according to what is better and new. So proactive organizations monitor attitudes and try to know the future requirements of current customers, anticipate changes in demand, and recognize emerging problems that could lead to opportunities.

Entrepreneurship plays a pivotal role in economic growth and a reason for the development of societies due to its vital role in creating job opportunities and stimulating innovation and creativity (Hassanain, 2020).

The strategic entrepreneurship is represented by the desire of higher education institutions to strategic change in some stages of implementation, the development of the ability to analyze internal and external factors. And the desire to develop skills and capabilities related to strategic management (Al-Buhairi, 2011). Entrepreneurship strategies deal with planning, organizing, risk bearing and creativity in the performance of universities (Al-Najjar and Al-Ali, 2010). Strategic Entrepreneurship is achieved when universities seek to provide the material and human resources necessary to achieve creativity in production methods, distinction and uniqueness in the product, innovation in production methods, and the benefit from Technology in all operations, and the risk of changing traditional ways of working (Paek \& Lee, 2017). Thus, the researcher believes that the application of leadership strategies in organizations requires risk, initiative, creativity, uniqueness or distinction, and innovation.

And the application of entrepreneurship strategies at the university level is based on adopting creative activities in order to invest in innovative and unique opportunities that develop and improve the university outputs (Abdel-Fattah, 2016). According to the great importance that universities can achieve when implementing entrepreneurship strategies, the extent to which entrepreneurship strategies are applied in universities in Israel has come into question, so the current study came to identify the reality of using entrepreneurship strategies in higher education institutions in Israel from the point of view of their employees.

\subsection{Problem and questions of the study}

The reality experienced by educational institutions in Israel does not require much effort to diagnose it, and it is generally in constant development, and despite Israel's interest in developing education in all its institutions, the researcher noticed, depending on her specialization and her work as a faculty member, that there are some aspects that need development, especially which regard to the policies of initiation and excellency, in addition to the 
community's complaint about some educational services provided to students in universities, and based on the results of many studies that confirmed the effectiveness of using entrepreneurship strategies in higher education institutions in improving outcomes, such as the study of Paek and Lee (2017), Al-Jubouri (2020), Sakarnah (2008), Al-Nefaiei (2015) \& Al-Qahtani (2019), these reasons as a whole formed a strong motivation for the researcher to investigate the degree of using entrepreneurship strategies in higher education institutions in Israel from the viewpoint of their employees. More specifically, the main question was: What is the reality of using entrepreneurship strategies in higher education institutions in Israel from the viewpoint of their employees? The following questions are divided into:

\section{Sub-questions:}

1. What is the reality of using excellence strategy in higher education institutions in Israel from the viewpoint of their employees?

2. What is the reality of using risk strategy in higher education institutions in Israel from the viewpoint of their employees?

3. What is the reality of using Creativity strategy in higher education institutions in Israel from the viewpoint of their employees?

\subsection{Importance of the study}

The importance of this study emerged from the urgent need to identify the degree of using entrepreneurship strategies in higher education institutions in Israel from the viewpoint of their employees because of the rapid technical, social and educational changes in Israel, so the importance of this study comes from its results, and the impact of these results on those in charge of education in Israel, and the importance of this study can be shown as follow:

\section{Theoretical importance:}

- Enrich the theoretical aspect regarded using entrepreneurship strategies in higher education institutions in Israel, as the researcher hopes that the study results contribute in enriching Israel library in this field.

- This study is expected to open up new doors in the field of using entrepreneurship strategies in higher education institutions, to conduct new studies to promote or deny the findings of this study.

\section{Applied practical aspect:}

- Providing a feedback about the using entrepreneurship strategies in higher education institutions in Israel to the educational leaders.

- It hoped to benefit from the findings and recommendations of this study the researchers and those interested in using entrepreneurship strategies in higher education institutions.

- It is hoped that this study findings help decision-makers in Israel in identifying the degree of using entrepreneurship strategies in higher education institutions in Israel, to help them in making appropriate decisions to improve the educational process.

\subsection{Terminology}

The study adopting identifying the following terms:

Entrepreneurship strategies: are defined as: "The set of procedures that a person or group of people undertakes in order to create a new entrepreneurial project with the aim of providing something distinctive that fulfills the desires of customers, and is added to the product, service, method or procedures (Al-Mahasna, 2013, p 151)." The researcher defines entrepreneurial strategies in this study procedurally with the methods and procedures practiced by the h higher education institutions in Israel within three basic dimensions: (risk, excellence, and creativity), and this study will be measured by the tool prepared to measure it.

\subsection{Study limitations}

The results of this study are determined by the nature of the sample and the tool of the study, as follows:

- The sample: it is limited to the higher education institutions employees.

- The temporal boundary: it is limited to the academic year 2020- 2021.

- Objective limit: identifying the degree of using entrepreneurship strategies in higher education institutions in Israel from the viewpoint of their employees.

\subsection{Variables}

The study includes three dependent variables, namely:

- The degree of using risk strategy in higher education institutions in Israel from the viewpoint of their employees.

- The degree of using excellence strategy in higher education institutions in Israel from the viewpoint of their employees.

- The degree of using creativity strategy in higher education institutions in Israel from the viewpoint of their 
employees.

\section{Previous studies}

The study of Tarihi (2020) aimed at determining the relationship between cognitive styles and entrepreneurial tendencies of students. The research was carried out in five different academic units at Pamukkale University. In this context, a questionnaire was applied to associate degree and undergraduate students and 680 students were reached. As a result of the research; A significant relationship was found between the cognitive styles and entrepreneurship tendencies of the students studying in higher education. Accordingly, students with fieldindependent cognitive style characteristics show more entrepreneurship tendency than field-dependent students. In addition, a significant relationship was found between the cognitive styles and entrepreneurial tendencies of the students with associate degree. Students who have independent independent cognitive style at the associate level are found to be more entrepreneurial than the students with field dependent cognitive style. However, the significant difference between these two variables was not found among the undergraduate students. In addition, a significant relationship was found between income level and cognitive style.

Ray Al-Jubouri (2020) conducted a study aimed at identifying the impact and relationship between Entrepreneurial strategies and smart organizations at the University of Mosul. In order the purpose of reaching the research goals, the questionnaire was used as a main tool for data collection and the AMOS program was used to test hypotheses. The analytical descriptive approach was used in dealing with theoretical and applied research data. The University of Mosul was chosen as a field of research through an analytical study and the research sample consisted of (298) employees from the top and middle leaders at the University of Mosul. The research reached the most important results that contribute to clarifying the relationship between the variables of the study and its dimensions, and the need for the university to rely on leadership strategies in all its dimensions because of its developmental impact in building smart organizations, which help the university to adapt to the fluctuating environmental conditions.

The study of Huang (2020) aimed at determining the Satisfy degree of Teachers and Students toward Sustainable Development Mode of Entrepreneurship Education in Chinese Universities, The data are derived from 12,269 valid questionnaires in student volume and 1,241 valid questionnaires in teacher volume from top universities in China, and regression and variance analyses were applied. The findings show that the overall satisfaction of teachers and students is higher than the national average. There are significant differences in the overall satisfaction of different types of teachers and students. Teachers are most satisfied with the organizational leadership measures of the universities in entrepreneurship education and least satisfied with the lack of professional human resource management strategies for entrepreneurship education teachers. Students are most satisfied with entrepreneurship policy and least satisfied with entrepreneurship learning, especially that entrepreneurship theory learning and practice learning are closely combined with students' majors. The overall satisfaction of students of entrepreneurship education mainly comes from the influence of "entrepreneurship policy dividend," entrepreneurship learning, and entrepreneurship competition and entrepreneurship practice, which go hand in hand. The overall satisfaction of teachers is most affected by the satisfaction of organizational leadership, followed by the satisfaction of mechanism guarantee and teaching management.

The study of Al-Mashareqah (2019) aimed to investigate the role of faculties of administrative and economic sciences in the creation of innovative, creative and entrepreneurial graduates in the Palestinian universities. The paper looks at some of the different perspectives on entrepreneurship education, with an emphasis on several entrepreneurship education trends in higher education institutions in Palestine. To achieve this, the researchers developed a tool for collecting the required data (a questionnaire) that was verified, validated, and then distributed to a sample of 97 faculty members representing $81 \%$ of the study population. To analyze the collected data, the researchers used the descriptive statistics indicators, in addition to quantitative statistics methods such as multiple regression analysis, independent samples $\mathrm{t}$ - test, ANOVA and variance analysis test. The results showed that the contribution of the faculties of administrative and economic sciences in the creation of innovative, creative and entrepreneurial graduates in the Palestinian universities was medium. The results also found no significant differences in the degree of contribution of the faculties of administrative and economic sciences in the entrepreneurial empowerment attributed to the variables of university education level and position. Meanwhile, differences were found in the variable of "specialization of the faculty member".

Al-Qahtani (2019) conducted a study aimed at identifying the reality of Entrepreneurial leadership dimensions (Entrepreneurial creativity, Strategic Vision, Reactiveness, Bear the risks and Investment Opportunities) for academic leaders in the Imam Abdul Rahman bin Faisal University. To achieve this, the study used the analytical descriptive approach, and the questionnaire as a tool for data collection applied to the study sample of 82 academic leaders. The data processed by Statistical Package Program. The study reached several of results: The Entrepreneurial leadership requirements are available in a medium degree, came in the first order "Strategic Vision", followed by the "Entrepreneurial creativity", "Proactivity", "Investment Opportunities" and finally "bear the risks". There are no significant differences to the variable "gender", "scientific rank" or 
"administrative location" or "experience years". The study concluded with several recommendations, the most important of which are: The need to exercise entrepreneurial leadership in universities is a strategic response to deal with challenges, opportunities and adapt to the higher education demands. By providing a stimulating work environment, attracting creativity minds, building a proactive organizational culture, activating entrepreneurial strategies, and adopting risk-taking to move the university from strategic position to an entrepreneurial position.

Al-Awda (2018) study sought to determine the availability of the characteristics of (administrative entrepreneurship) among the academic leaders in the Saudi universities and the obstacles hindering their achievement, in addition to trying to identify the mechanisms of activating the characteristics of (administrative entrepreneurship) among the academic leaders in the Saudi universities. To achieve the objectives of the current study, the researcher relied on the descriptive approach. The questionnaire was applied to a sample of Academic leadership in Saudi universities represented by university agents, deans of colleges, and deans of deanships: King Saud - Imam Mohammed bin Saud - King Khalid -Hail. The study found some of the most predominant results are the availability of some of the characteristics (administrative entrepreneurship) of the academic leaders in Saudi universities, which is the responsibility to work and love of achievement to a high degree of self-confidence is available to a medium degree, while the risk and creative initiatives of academic leaders in Saudi universities have been available to a poor degree. The study also revealed that there are significant differences at the level of significance of 0.05 in the degree of availability of the characteristics of (administrative entrepreneurship) (risk, creative initiatives) among academic leaders due to the variables (experience, university). The study also identified a number of obstacles that hinder the achievement of administrative entrepreneurship among the academic leaders in Saudi universities. The most prominent of these are the lack of qualified university departments and units to support the activities of the administrative entrepreneurship, and the reliance on the typical thinking in running the administrative affairs of the university. The members of the study have agreed on a number of mechanisms to activate the administrative entrepreneurship among the academic leaders in the Saudi universities. The most important of these is the necessity of providing material and moral incentives to the pioneers of ideas to develop the performance and delegating competent and creative individuals to carry out responsibilities of great importance and attracting the creators to work in the various departments and university units. The study presented a number of recommendations, emphasizing the tenure on selecting Saudi academic leaders who have the characteristics of (leading management), as well as encouraging academic leaders in Saudi universities to adopt the characteristics of (managerial Entrepreneurship) and setting up training programs and workshops among Saudi academic leaders to enhance Entrepreneurship) that are practiced at low levels, including risk appetite and creative initiatives.

Paek and Lee (2017) conducted a study aimed at identifying the relationship between the applying of entrepreneurship strategies and achieving the competitive advantage of existing companies. The study used digital TV production companies in Beijing in China as a model. The study used the qualitative approach, and the interview was used to collect data from the individuals of the study sample. And, the researcher selected a sample of (27) managers and administrative employees from the employees of the higher categories of television companies, and the findings of the study showed a statistically significant relationship between the applying of each dimension of entrepreneurship, which is (responding to the surrounding environment, catching opportunities, strategic flexibility, and Organizational learning) and between the level of achieving competitive advantage.

Al-Nefaiei (2015) conducted a study aimed at identifying the entrepreneurial strategies adopted in Saudi universities through a field study conducted on King Saud University (KSU) based on the following dimensions: creativity, uniqueness, and growth. The study also identified the main differences in the respondents' views. To achieve these goals, the analytical descriptive approach was applied using a questionnaire consisting of entrepreneurial strategies variable to measure the above three dimensions and investigate the perspectives of faculty deans, deputies, and deanship deans and deputies as well as heads and deputy heads of departments at (KSU). The study came up with a number of key conclusions: respondents largely agree on the above three dimensions as determinants of the status of the entrepreneurial strategies at (KSU). According to respondents, these dimensions are categorically classified. Growth dimension ranked first, the creativity dimension listed second while the uniqueness dimension ranked third. In the growth dimension, results reflect a broad agreement on the paragraph that reads, "University enters into coalition agreements with (technical and media firms, entrepreneurial universities and electronic education companies)". In the creativity dimension, results show a broad agreement on the paragraph that reads, "University offers new services (e.g. electronic, educational, health, research, construction, technology and community services)". In the uniqueness dimension, the paragraph that reads, "university hires highly distinguished faculty members" lists first. Results of differences in respondents reflected considerable statistical differences in growth dimension in favor of males against females, statistical differences attributed to the workplace in creativity dimension in favor of health faculties against literary- ones, statistical differences attributed to the administrative position in growth dimension in favor of deans, deputies, heads and deputy heads of departments. The study concluded with a number of scientific and academic recommendations.

Sakarnah (2008) study aimed to develop "Entrepreneurship strategies to achieve competitive Advantages, 
and improve the performance of telecom companies in Jordan," . The researcher developed a model to examine the relationship between Entrepreneurship strategies (creativity, creativity, risk tacking, reactiveness and uniqueness) and competitive advantage (cost leadership, differentiation, alliance). The data were collected from (109) managers working in (4) Jordanian communication companies after submitting (140) questionnaires. The variables analysis was processed by descriptive statistical analysis, means, standard deviation, coefficient variance, and by use of inferential statistics: the correlation, the effects were tested by multiple regression and linear regression, The main findings were that there are positive relations between Entrepreneurship strategies and competitive advantage in communication companies, and there are positive relations between elements Entrepreneurship strategies and competitive advantage in communication companies, and there are positive effects between the change in Entrepreneurship strategies and competitive advantage in communication companies.

\section{Method and procedures}

\subsection{Methodology}

This study aimed at investigating the degree of using entrepreneurship strategies in higher education institutions in Israel from the viewpoint of their employees, so the study used the descriptive survey method which regarded suitable for this study.

The study population consisted of all employees who work in higher education institutions in Israel. And a sample consisted of (102) employees were chosen in arbitrary method.

\subsection{The Study tool}

To investigate the degree of using entrepreneurship strategies in higher education institutions in Israel from the viewpoint of their employees, a questionnaire was developed by the researcher.

\subsection{Validity of the study tool}

To ascertain the validity of the study tool, content validity was used by viewing the questionnaire to (10) arbitrators of the faculty members who specialize in educational administration, so as to take their opinions on the content of the tool, and the adequacy of paragraphs, and the need to modify or delete any paragraph, and any comment they think it is necessary, in the light of the observations of the arbitrators, some items were modified, but no item deleted, and the researcher found that the paragraphs were correlated to their dimensions, as the agreement degree between the arbitrators reached (96\%), and this percentage is regarded suitable for the purposes of this study.

\subsection{Reliability of the study tool}

Research tool reliability was assured reliability by using the (Test- retest), and by applying it on (18) employee from outside the Research sample, and Pearson correlation coefficient was calculated, and the value of reliability coefficient was (0.92), and this is an acceptable value for the purposes of the Research.

The degree of using entrepreneurship strategies in higher education institutions in Israel from the viewpoint of their employees was determined by dividing the degrees to three levels (high, medium, low) based on the following equation:

The highest value - the lowest value / number of levels $=(5-1) / 3=4 / 3=1.33$.

Thus it was adopted the following Criterion to determine the degree of using entrepreneurship strategies in higher education institutions in Israel from the viewpoint of their employees:

- Low degree: represent grades between (1-2.33).

Medium degree: represent grades between (2.34- 3.67).

.( High degree of exercise: represent grades between (3.68- 5.00).

\subsection{Statistical treatment}

To answer the questions of the study the appropriate statistical methods were used as follow:

- To answer the first, second and third question, the averages and standard deviations were used.

\section{Study results and discussion}

Findings of the study and its discussion: The study presents the findings that reached through the respondents of the sample to their questions, as follows:

\subsection{Findings related to the first question that stated: "What is the reality of using excellence strategy in} higher education institutions in Israel from the viewpoint of their employees?"

To answer this question, arithmetic averages and standard deviations were calculated for the reality of using the Excellence Strategy in higher education institutions in Israel from the viewpoint of their employees for the dimension as a whole, and for each of its items, and Table (1) shows that. 
Table (1): Arithmetic averages, standard deviations, and ranks of the reality of using the strategy of excellence in higher education institutions in Israel from the viewpoint of their employees for the field in general, and for each of its paragraphs, arranged in descending order.

\begin{tabular}{|c|c|c|c|c|c|c|}
\hline dimension & no. & The question & $\begin{array}{c}\text { arithmetic } \\
\text { average }\end{array}$ & $\begin{array}{l}\text { standard } \\
\text { deviation }\end{array}$ & rank & degree \\
\hline \multirow{6}{*}{ Excellence } & 2 & $\begin{array}{l}\text { The university administration provides } \\
\text { unique technological services. }\end{array}$ & 4.11 & 0.52 & 1 & High \\
\hline & 5 & 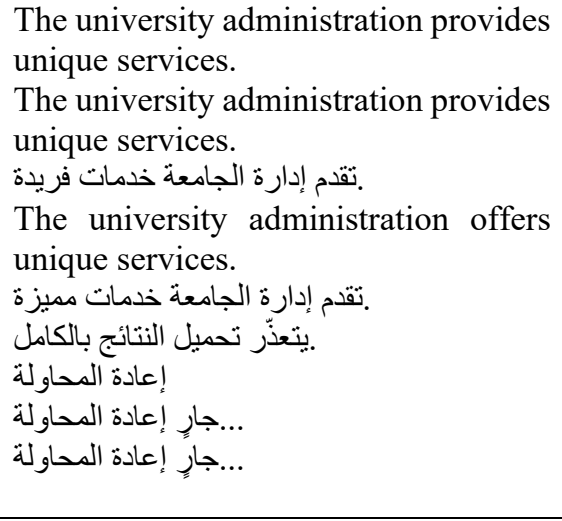 & 3.92 & 0.59 & 2 & high \\
\hline & 1 & $\begin{array}{l}\text { The university administration is } \\
\text { committed to quality standards. }\end{array}$ & 3.87 & 0.55 & 3 & high \\
\hline & 4 & $\begin{array}{l}\text { The university administration focuses } \\
\text { on the quality of the outputs. }\end{array}$ & 3.77 & 0.63 & 4 & high \\
\hline & 3 & $\begin{array}{l}\text { The university administration } \\
\text { contracts with external experts. }\end{array}$ & 3.12 & 0.64 & 5 & medium \\
\hline & \multicolumn{2}{|c|}{ The whole degree of the Excellence dimension } & 3.76 & 0.24 & & igh \\
\hline
\end{tabular}

It is noted from Table (1) that the reality of using the strategy of excellence in higher education institutions in Israel from the point of view of its employees came to a high degree, as the arithmetic average reached (3.76) with a standard deviation (0.24), and this result means that the university pays great attention to providing technical services for employees and students, Paragraph (2) came in the first rank, which states that "The university administration provides unique technological services", with a mean (4.11), and a standard deviation (0.52), which means that the university keeps pace with modern digital developments; This result may be attributed to the university administration's interest in technical development, and the constant endeavor to take advantage of the facilities provided by modern digital technologies. Therefore, universities provide in one way or another various qualitative technical quality services, and this can be particularly noticeable in the services related to access to databases and utilization. Paragraph (3) which states that "the university administration contracts with external experts" came in the last rank, with an arithmetic mean (3.12) and a standard deviation (0.64). This result means that the university administration contracted with external experts is not up to the desired level, as it came with a medium degree. This may be attributed to the university appointment system that reduces the number of temporary and external contracts.

This finding is differed from the study of Al-Qahtani (2019) finding which concluded that the entrepreneurial leadership requirements are available in a medium degree, and with the result of Al-Mashareqah (2019) which showed that the contribution of the faculties of administrative and economic sciences in the creation of innovative, creative and entrepreneurial graduates in the Palestinian universities was medium. While this finding is agree with the finding of the study of Al-Awda (2018) which concluded that the availability of some of the characteristics (administrative entrepreneurship) of the academic leaders in Saudi universities, which is the responsibility to work and love of achievement to a high degree

4.2. Findings related to the first question that stated: "What is the reality of using risk strategy in higher education institutions in Israel from the viewpoint of their employees?"

To answer this question, arithmetic averages and standard deviations were calculated for the reality of using the risk Strategy in higher education institutions in Israel from the viewpoint of their employees for the dimension as a whole, and for each of its items, and Table (2) shows that. 
Table (2): Arithmetic averages, standard deviations, and ranks of the reality of using the strategy of risk in higher education institutions in Israel from the viewpoint of their employees for the field in general, and for each of its paragraphs, arranged in descending order.

\begin{tabular}{|c|c|l|c|c|c|c|}
\hline \multirow{6}{*}{ dimension } & no. & \multicolumn{1}{c|}{ The question } & $\begin{array}{c}\text { arithmetic } \\
\text { average }\end{array}$ & $\begin{array}{c}\text { standard } \\
\text { deviation }\end{array}$ & rank & degree \\
\hline & 6 & $\begin{array}{l}\text { The university administration } \\
\text { simulates modern developments in the } \\
\text { universities of developed countries. }\end{array}$ & 3.74 & 0.54 & 1 & high \\
\cline { 2 - 7 } & 10 & $\begin{array}{l}\text { The university administration is } \\
\text { expanding its facilities continuously. }\end{array}$ & 3.69 & 0.41 & 2 & high \\
\cline { 2 - 7 } & 7 & $\begin{array}{l}\text { The university administration adopts } \\
\text { the latest educational programs. }\end{array}$ & 3.51 & 0.48 & 3 & medium \\
\cline { 2 - 7 } & 9 & $\begin{array}{l}\text { The university administration offers } \\
\text { new high-priced services and projects. }\end{array}$ & 3.11 & 0.56 & 4 & medium \\
\cline { 2 - 7 } & 8 & $\begin{array}{l}\text { The university administration seeks to } \\
\text { develop its facilities regardless of } \\
\text { costs. }\end{array}$ & 3.08 & 0.41 & 5 & medium \\
\hline
\end{tabular}

It is noted from Table (2) that the reality of using the risk strategy in higher education institutions in Israel from the point of view of its employees came to a medium degree, as the arithmetic mean was (3.43) with a standard deviation (0.29), and this result means that there are some deficiencies in the application of the risk strategy Especially with regard to launching new projects, and adopting the implementation of expensive projects. And paragraph (6) came in first rank, which states that: "The university administration simulates modern developments in the universities of developed countries", with an average (3.74) and a standard deviation (0.54). This result may be attributed to the ambition of universities to go on with the developments that occur in the technical side on the world, especially with regard to the digital economy, while Paragraph (8) which states "The university's administration seeks to develop its facilities regardless of costs" came in last rank with an arithmetic mean (3.08) and a standard deviation (0.41). This result may be attributed to the university applied system which does not allow risk in any way, and sets the highest financial ceiling allowed to be spent within strict controls.

This finding is agree With the study of Al-Qahtani (2019) finding which concluded that the entrepreneurial leadership requirements are available in a medium degree, and with the result of Al-Mashareqah (2019) which showed that the contribution of the faculties of administrative and economic sciences in the creation of innovative, creative and entrepreneurial graduates in the Palestinian universities was medium. While this finding is differ from the finding of the study of Al-Awda (2018) which concluded that the availability of some of the characteristics (administrative entrepreneurship) of the academic leaders in Saudi universities, which is the responsibility to work and love of achievement to a high degree

4.3. Findings related to the first question that stated: "What is the reality of using creativity strategy in higher education institutions in Israel from the viewpoint of their employees?"

To answer this question, arithmetic averages and standard deviations were calculated for the reality of using the creativity Strategy in higher education institutions in Israel from the viewpoint of their employees for the dimension as a whole, and for each of its items, and Table (3) shows that. 
Table (3): Arithmetic averages, standard deviations, and ranks of the reality of using the strategy of creativity in higher education institutions in Israel from the viewpoint of their employees for the field in general, and for each of its paragraphs, arranged in descending order.

\begin{tabular}{|c|c|c|c|c|c|c|}
\hline dimension & no. & The question & $\begin{array}{l}\text { arithmetic } \\
\text { average }\end{array}$ & $\begin{array}{l}\text { standard } \\
\text { deviation }\end{array}$ & rank & degree \\
\hline \multirow{6}{*}{ Creativity } & 12 & $\begin{array}{l}\text { The university administration seeks to } \\
\text { create new methods to provide services to } \\
\text { students and the local community. }\end{array}$ & 4.01 & 0.44 & 1 & high \\
\hline & 13 & $\begin{array}{l}\text { The university administration presents } \\
\text { development plans that keep on with } \\
\text { technical development. }\end{array}$ & 4.14 & 0.37 & 2 & high \\
\hline & 15 & $\begin{array}{l}\text { The university administration rewards } \\
\text { employees who provide innovative ideas. }\end{array}$ & 3.87 & 0.57 & 3 & high \\
\hline & 11 & $\begin{array}{l}\text { The university administration adopts } \\
\text { administrative creativity to achieve a } \\
\text { competitive advantage. }\end{array}$ & 3.73 & 0.84 & 4 & high \\
\hline & 14 & $\begin{array}{l}\text { The university administration presents its } \\
\text { programs in innovative methods. }\end{array}$ & 3.59 & 0.39 & 5 & $\begin{array}{c}\text { mediu } \\
\mathrm{m}\end{array}$ \\
\hline & \multicolumn{2}{|r|}{ The whole degree of the creativity dimension } & 3.87 & 0.27 & \multicolumn{2}{|c|}{ high } \\
\hline
\end{tabular}

It is noted from Table (3) that the reality of using the innovation strategy in higher education institutions in Israel from the point of view of its employees came to a high degree, as the arithmetic average reached (3.68) with a standard deviation (0.22), and this result may be attributed to the interest in discovering gifted students and employees and taking care with them. And Paragraph (12) came in the first rank, which states that "The university administration seeks to create new methods to provide services to students and the local community" with a mean (4.01) and a standard deviation (0.44). This result may be attributed to the university administration's interest in community partnership, and in upgrading the professional and academic level of students, and the constant pursuit of applying the principles of the knowledge economy, while Paragraph (14) which states "The university administration presents its programs in innovative methods" came in last rank with an average of (3.59) and a standard deviation (0.39). This result may be attributed to the university administration's conviction that creativity is the basis for development, and that creativity leads to uniqueness, and thus creates added value for the programs offered by the university.

This finding is differed from the study of Al-Qahtani (2019) finding which concluded that the entrepreneurial leadership requirements are available in a medium degree, and with the result of Al-Mashareqah (2019) which showed that the contribution of the faculties of administrative and economic sciences in the creation of innovative, creative and entrepreneurial graduates in the Palestinian universities was medium. While this finding is agree with the finding of the study of Al-Awda (2018) which concluded that the availability of some of the characteristics (administrative entrepreneurship) of the academic leaders in Saudi universities, which is the responsibility to work and love of achievement to a high degree

\section{Recommendations and suggestions}

In the light of the findings of this study, the researcher recommends the following:

- Adopting the provision of the necessary financial support by the university administration to provide the latest educational programs.

- Adopting the provision of the necessary financial support by the university administration to provide new high-priced services and projects.

- Adopting new legislation by the university administration that allows contracting with external experts

- Adopting the provision of necessary support by the university administration to develop its facilities.

- Adopting offering programs in innovative ways by the university administration.

\section{References}

Abdel-Fattah, R. (2016), the Leadership Strategy and its Impact on the Development of Distinguished Performance among Department Heads of Faculties of Physical Education and Sports Sciences, Journal of Administrative and Economic Research, 22 (95), 667-692

Al-Awda, I. (2018), The Reality of the Characteristics of Administrative Leadership among Academic Leaders in Saudi Universities, Arab Center for Education and Development, 25 (1) 11-88.

Al-Buhairi, S. (2011), Management Reform Entrances, Organizational Development, Training and Performance Evaluation,(Unpublished Master Thesis), British Arab Academy for Higher Education, London. 
Al-Douri, Z. (2014), Strategic entrepreneurship from the perspective of customer value according to the philosophy of the blue ocean strategy, Al-Koot Journal of Economic and Management Sciences, 14 (1), 203-217.

Ali, A. (2017), Strategic entrepreneurship and its Reflection in the Development of Organizations - The Independent High Electoral Commission as a Model, Al-Ghary Journal for Economic and Administrative Sciences, 14 (2), 47-86.

Al-Jubouri, S. (2020), Building smart organizations through leadership strategies and their role in crisis management: An analytical study of a sample of the colleges of the University of Mosul, Al-Rafidain Development Journal, 39 (1), 40-61.

Al-Mahasna, I. (2013), Department of Job Performance Evaluation between Theory and Practice, 1st Edition, Amman: Jarir House for Publishing and Distribution.

Al-Mashareqah, O. (2019), The Role of Faculties of Administrative and Economic Sciences in Creating Entrepreneurship and Creativity among Graduate Students in Palestinian Universities: From the Perspective of Faculty Members, Al-Quds Open University, Journal for Human and Social Research, 50 (1), 15-31.

Al-Nafei, M. (2015), the Status Of Entrepreneurial Strategies In Saudi Arabian Universities: A Field Study conducted on King Saud University, Journal Public Administration, 55 (4), 663-718.

Al-Najjar, F. \& Al-Ali, A. (2010), Entrepreneurship and Small Business Administration, 1st Edition, Amman: Hazem House for Publishing and Distribution.

Al-Qahtani, A. (2019), the Reality of Entrepreneurial Leadership Dimensions in Saudi Universities: An Empirical Study in Imam Abdul Rahman bin Faisal University, Journal of Arts, Literature, Humanities and Sociology, 40 (1), 216-233.

Hassanain, M. (2020), The Roles of the Centers of Entrepreneurship in Application to the Center for Job Development and Entrepreneurship at the University of Alexandria, Journal of Education - Sohag University. 73(2), 971-1042.

Hitt, E. (2007), strategic management ,the 7 th edition by Thomson Learning, Inc.

Ireland, R. (2003), a model of strategic entrepreneurship: the construct and its dimensions, Journal of Management, 29(6), 429- 487.

Kavousy, E. (2010) Cultural Entrepreneurship Strategies in Iran, Serbian Journal of Management, Science and Research Branch of Islamic Azad University, 2(5), P. 227-241.

Kittana, K. and Agha, A. (2012), Elements of Entrepreneurial Strategies and their Impact on Product Creativity Dimensions, Journal of Administrative and Economic Research, 1 (1), 112-139.

Kuratko, F. (2014), Strategic Entrepreneurship: Exploring Different perspectives of an Emerging Concept: Conference on Entrepreneurship: Theory and practice, Germany Journal, 33(1), 1-17.

Paek, B. \& Lee, H. (2017), Strategic entrepreneurship and competitive advantage of established firms: evidence from the digital TV industry, International Entrepreneurship and Management Journal, 7(1), 1136511382.

Sakarneh, K. (2008), Entrepreneurial Strategies and their Role in Achieving Competitive Advantage (Field Study on Telecommunications Companies in Jordan, Baghdad College of Economic Sciences Journal, 17 (1), $77-112$

Tarihi, Y. (2020), the relationship between cognitive style and entrepreneurship tendency: a practice in pamukkale university, Journal of Graduate School of Social Sciences. 22(3), 1109-1124. 